\title{
Inflationary Trends in India: A Pre and Post Reform Study
}

\author{
Indu Bala \\ Department of Economics, Panjabi University, Patiala, India. \\ Dhiraj Sharma \\ School of Management Studies, Panjabi University, Patiala, India.
}

\begin{abstract}
The present paper attempts to explore the nature, trends and patterns of inflation in India during 1980-2016. The selected time period has been trifurcated purposively into three-time spans namely, pre-reform period (1980-90), after reform period (1991-2000) and subsequent period (2001-16). The endeavour of the paper is to examine the dynamics of inflation over the three-time spans from 1980-2016 in the Indian economy. It has been found that the inflation, based on WPI and CPI, is continuously rising since 1980. Up to 1995, the trend in CPI and WPI were same and there was no significant difference between them. However, after 1995, CPI has recorded larger growth as compared to WPI. Such trend has also continued in the subsequent period. The study reveals that this trend may be attributed to change in the composition of WPI and CPI since weights of primary articles have declined in WPI whereas such weights have registered a considerable increase in the categories of manufacturing, fuel and power. The shift in weights overtime provides us with an indicator of the changing production and use pattern of the commodities in the Indian set up. Further, the weights of food items have reduced overtime in case of CPI and such weights have been increased in respect of clothing, housing and fuel. The changes witnessed in weights of CPI are indicators of a growing economy. This study further contributes in the available literature by comparing the patterns of Inflation in Pre and Post-reform Period.
\end{abstract}

Key Words: Inflation, Wholesale Price Index (WPI), Consumer Price Index (CPI), Money Supply, Industrial production (IIP).

JEL Codes: E30, E31, E50, E51

\section{INTRODUCTION}

Inflation is one of the most important macroeconomic variables which needs to be tackled prudently. It has been recognised in the economic literature that inflation is obvious consequence of the growth process. Though, this opinion is accepted with some reservation. The inflation as a macro variable does not exist in isolation, it makes pattern with other important macro variables. The understanding of such pattern provides in depth understanding of the working of the economy which, in turn, provides adequate instruments in the hands of authorities to control the menace of inflation. Though, divergent opinions exist regarding relationship among these variables but adequate theory has been developed in due course. The movement of these variables may vary from developed to developing countries. The simultaneous movement of these

Journal of Technology Management for Growing Economies Vol. 9, No. 2 October, 2018 pp. 151-161

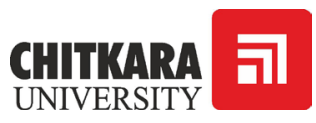

C 2018 by Chitkara University. All Rights Reserved. 
Bala, I.

Sharma, D. variables may create sterilization effect on the performance of other variables. The concrete modelling of these variables with the inflation has been taken care in the ensuing chapters. India is a developing country and has a long history of inflation. The pattern of relationship among these variables may be different from the established theory and what had been experienced in the developed countries. Moreover, the authorities' may work out whether the inflation should be controlled through demand management, supply management or the combination of both.

There has been plenty of studies on inflation in India. Most of these studies generally follow either a monetarist or a structuralist approach to determine inflation in India. According to Pandit (1993) Indian government was giving over importance to the demand-pull factors and ignored the cost push. The paper also emphasised that contractionary fiscal and monetary policies, cannot be replaced for efficient resource utilization. On the contrary, it may have detrimental effects on the country.

Gary (1995) also studied the inflation in Nigeria for the time period between 1960 and 1993 and found out that increase in money supply is primarily responsible for inflation in Nigeria. Also, devaluation and agroclimatic conditions played a prominent role. Similarly, Lim and Adedeji (1997) tried to find out the major factors causing inflation in Turkey for the period between 1970 and 1995. The paper used Johansen's cointegration approach and came up with a conclusion that money supply, wages, export and import prices have positive impact on Inflation. On the contrary, exchange rate and inflation are negatively related in turkey. Domac and Carlos (1998) examined the factors affecting price rise in Albania. They used Granger Causality tests to find out the relation between $\mathrm{M} 1$ and the exchange rate.

The focus of the Reserve Bank of India (RBI) has moved from monetary targeting to a multiple approach. In light of this Callan and Chang, (1999), examines as to which factor provide the most useful information about future inflationary tendencies. By using a VAR technique, it has been found out that, developments in the monetary aggregates continue to be an important indicator of future inflation. The import prices and exchange rate and are also equally important.

John (2003) has studied post liberalization data to find out the causality between monetary aggregates and exchange rates. Vector Autoregressive (VAR) technique has been used to figure out as to which monetary aggregate explains the inflation in the best way. It has been concluded that the broad money measure (M3) is better.

Bishnoi and Koirala (2006) examined the dynamics of inflation models in Nepal, for this purpose they have used a test of cointegration between inflation

Journal of Technology Management for Growing Economies, Volume 9, Number 2, October 2018 
and its explanatory variables. They have used the Error Correction Mechanism (ECM) to find out the relationship. It was established that there was long period cointegrating relationship among relevant variables. Srinivasan et.al. (2006), however examined an augmented Phillips curve to study the outcomes of supply shocks on inflation in India. By using Ordinary Least Square framework it was found that supply shocks did not have a permanent effect on both headline inflation and core inflation. More, Also the the author is of the opinion that monetary policy in India is more inclined towards the core inflation and headline inflation has been ignored.

Mosayed and Mohammad (2009) also studied the factors affecting inflation in Iran for the data from 1971-2006. They have used Autoregressive and Distributed Lag (ARDL) model and came to the conclusion that exchange rate, money supply, gross domestic product, and foreign prices are equally responsible for high prices in Iran. On the same lines Sahadudhen (2012) examined the factors affecting inflation in India on the quarterly data (1996 Q1 to 2009 Q3) by making use of the cointegration and Vector Error Correction model. It was concluded that GDP and broad money have a good effect on inflation.

\section{DATABASE AND METHODOLOGY}

To explore the dynamics of inflation in Indian economy, monthly data for the period from 1980 till 2016 has been used. This period encompasses the eras of high to moderate inflation hence; represents adequate variation in the data. Relevant macroeconomic variables have been obtained from official website of Ministry of Statistics and Policy Implementation (www.mospi.gov.in), RBI (www.rbi.org.in). The data so obtained has been analysed by using various statistical techniques. Arithmetic mean, median, variance, skewness and kurtosis have been used for the general description of the variables.

\section{PRESENT STUDY}

Though, it cannot be denied that inflation is a perpetual problem and needed to be taken care always. But it is expected that with the change in the structure of the economy in terms of the sectoral distribution of the economy, the inflation may show different trends and patterns during the three period segments. As, the role of service sector has increased in recent decades and the share of agriculture in GDP has declined considerably in recent decade. Accordingly, reflection in the nature of inflation and its relationship with other variables are obvious consequences. Not only the structure of the economy has witnessed changes, under the influence of globalization and the consumerism has impacted the consumption pattern of the people. New things are appearing
Inflationary

Trends in India 
Bala, I.

Sharma, D. in the consumption basket of the people and some are disappearing from it. Therefore, it is interesting to study the nature and trends of inflation in India.

\section{INFLATION: NATURE AND TRENDS}

Inflation in India is measured by using mainly three price indices. Changes in the prices of goods at the wholesale price level are measured by the Wholesale Price Index (WPI) whereas changes in prices of goods and services at the retail level are measured by the Consumer Price Index (CPI). Another technique to measure changes in prices, apart from estimating price indices, is to use the Gross National Product (GNP) deflator which is the ratio of GNP at current prices to GNP at constant prices. However, GNP numbers are not used to measure inflation in India because of the limited frequency with which these are estimated, just once every quarter.

\section{WHOLESALE PRICE INDEX (WPI)}

The changes experienced in the wholesale price level are gauged by the Wholesale Price Index (WPI). WPI for the base year 2004-05 are based on the weighted average of 676 commodities and 5482 price quotations which are taken into account while calculating the index. The constituents of WPI are categories between three categories - primary articles (food, non-food and minerals), fuel and power (coal, mineral oils and electricity) and manufactured products (food products, beverage, tobacco, textiles, wood, paper, leather, rubber and chemicals).

The WPI is a weighted average of three categories of commodities. The shift in weight overtime provides us an indicator of the changing production and use pattern of the commodities. These weights shift indicates the structural change in the economy. As the economy moves from lower level of growth to higher level the weights are expected to shift away from the primary commodities and in favour of manufactured and fuel and power. Indian economy has witnessed dramatic growth after the introduction of new economic policy in 1991. Moreover, the product mix pattern used in the economy is expected to change. Such inklings are apparent in the Indian economy. Table 1 reveals that weight of primary items has decreased to 20.1 percent in 2004-5 to from 22 percent in 1993-94. Its weight was 32.29 in 1981-81.

However, such weights have been seen increasing overtime in the categories of fuel and manufactured products. The growing economy is expected to experience such shifts (Table 1). The figures will be more revealing, if the shift in sub-categories is seen minutely. In primary articles, shares of food and non-food articles have witnessed decrease overtime. In the category of fuel and power, the weights of oils and coal have increased whereas decreased in

Journal of Technology Management for Growing Economies, Volume 9, Number 2, October 2018 
electricity component. So far, the weights in the manufactured products are concerned, the weight of traditional items has declined and it has increased in other items which are emerging important in the growth process.

Table 1: Wholesale Price Index Weights

\begin{tabular}{|l|l|l|l|}
\hline Commodity & $\mathbf{1 9 8 1 - 8 2}$ & $\mathbf{1 9 9 3 - 9 4}$ & $\mathbf{2 0 0 4 - 0 5}$ \\
\hline Commodities & $\mathbf{1 0 0}$ & $\mathbf{1 0 0}$ & $\mathbf{1 0 0}$ \\
\hline (A) Primary Articles & $\mathbf{3 2 . 2 9}$ & $\mathbf{2 2}$ & $\mathbf{2 0 . 1}$ \\
\hline Food Articles & 17.39 & 15.4 & 14.3 \\
\hline Non-Food Articles & 10.08 & 6.1 & 4.3 \\
\hline Minerals & 4.82 & 0.5 & 1.5 \\
\hline (B) Fuel and Power & $\mathbf{1 0 . 6 6}$ & $\mathbf{1 4 . 2}$ & $\mathbf{1 4 . 9}$ \\
\hline Coal & 1.26 & 1.8 & 2.1 \\
\hline Mineral Oils & 6.67 & 7 & 9.4 \\
\hline Electricity & 2.73 & 5.5 & 3.5 \\
\hline (C) Manufactured Products & $\mathbf{5 7 . 0 5}$ & $\mathbf{6 3 . 7}$ & $\mathbf{6 5}$ \\
\hline Food products & 10.14 & 11.5 & 10 \\
\hline Beverage and Tobacco & 2.15 & 1.3 & 1.8 \\
\hline Textiles & 11.54 & 9.8 & 7.3 \\
\hline Wood and Wood Products & 1.2 & 0.2 & 0.6 \\
\hline Paper and Paper Products & 1.99 & 2 & 2 \\
\hline Leather & 1.02 & 1 & 0.8 \\
\hline Rubber and Plastic & 1.59 & 2.4 & 3 \\
\hline Chemicals & 7.35 & 11.9 & 12 \\
\hline Non-Metallic & 2.48 & 2.5 & 2.6 \\
\hline Machinery and Tools & 7.63 & 8.3 & 10.7 \\
\hline Transport and Equipment & 6.27 & 8.4 & 8.9 \\
\hline Basic Metals and Alloys & 2.71 & 4.3 & 5.2 \\
\hline & 0.97 & 0 & 0 \\
\hline
\end{tabular}

Source: Office of the Economic Advisor, Ministry of Commerce

The WPI is a weighted average of three categories of commodities

\section{CONSUMER PRICE INDEX (CPI)}

Information regarding Consumer Price Index (CPI) in India is available in four formats namely (a) CPI for Industrial Labourers (IL); (b) CPI for Agricultural Labourers (AL); (c) CPI for Rural Labourers (RL); and (d) CPI for all India 
Bala, I.

Sharma, D. (or combined CPI) (CPI for urban Labourers was discontinued in April, 2010). India did not have one composite CPI before the start of all India CPI. For the earlier period, CPI (IL) is used as a representative of all India CPI. The broad items of consumption expenditure of CPI (IL) and CPI Composite are divided into 5 groups (a) Food; (b) Pan, Supari, Tobacco and Intoxicants; (c) Fuel and Light; (d) Clothing, Bedding and Footwear; (e) Miscellaneous (includes medical care, education, recreation and amusement.

Table 2: Weights Assigned to Consumer Price Index (Base2001)

\begin{tabular}{|l|l|}
\hline Particulars & Weights \\
\hline Food & 57 \\
Pan, Supari, Tobacco and Intoxicants & 3.15 \\
Fuel and Light & 6.28 \\
Housing & 8.67 \\
Clothing, Bedding and Footwear & 8.54 \\
Miscellaneous & 16.36 \\
\hline All Groups & 100 \\
\hline
\end{tabular}

Source: Ministry of Labour and Employment

Table 3: Weights Assigned to Combined Consumer Price Index (Base 2010)

\begin{tabular}{|l|l|}
\hline Particulars & Weights \\
\hline Food, Beverage and Tobacco & 49.71 \\
Fuel and Light & 9.49 \\
Housing & 4.73 \\
Clothing, Bedding and Footwear & 9.77 \\
Miscellaneous & 26.31 \\
\hline Total & 100 \\
\hline
\end{tabular}

Source: Ministry of Labour and Employment

The Table 2 and 3 depict that there is dramatic change in the weights assigned to different groups' overtime. The growth pattern experienced by the Indian economy during the first decade of this century must have compelled the authorities' changes weights of CPI overtime. The weights of food items have reduced overtime whereas such weights have increased in terms of clothing, housing and fuel. These are the indicators of a growing economy.

\section{CONSUMER PRICE INDEX (CPI) AND WHOLESALE PRICE INDEX (WPI) TRENDS}

CPI in India is considered as the true representative of inflation. For, it reflects the ground realities by tracking the prices of the goods that are purchased

Journal of Technology Management for Growing Economies, Volume 9, Number 2, October 2018 
on daily basis by general public. This index is very much popular in most of the countries. The primary disapproval for WPI is that general public does not transact on wholesale level on a daily basis; not considered as definitive ideal indicator of inflation. The CPI along with tracking prices of goods also includes services in indexing. In India now, bimonthly monetary policy makes the CPI as the base for the policy inputs.

The trends in the WPI and CPI are the indicators of many policy concerns in India. Moreover, inflation rates and its control are always on the agenda of respective governments. Therefore, to control and make the appropriate policy in this context it is important to watch the trends in the indices of CPI and WPI. The trends in the CPI and WPI are presented in Table 4.

Table 4: Consumer Price Index (CPI) and Wholesale Price Index (WPI) Series 1981 to $2016(2004-05=100)$

\begin{tabular}{|c|c|c|c|c|c|c|c|c|}
\hline \multicolumn{2}{|c|}{ Pre-Reform Period } & \multicolumn{2}{c|}{ Post-Reform Period } & \multicolumn{3}{c|}{ Subsequent Period } \\
\hline YEAR & WPI & CPI & YEAR & WPI & CPI & YEAR & WPI & CPI \\
\hline $\mathbf{1 9 8 1}$ & 16.40 & 19.56 & $\mathbf{1 9 9 1}$ & 44.21 & 45.77 & $\mathbf{2 0 0 1}$ & 86.06 & 98.78 \\
$\mathbf{1 9 8 2}$ & 17.18 & 21.10 & $\mathbf{1 9 9 2}$ & 49.31 & 51.17 & $\mathbf{2 0 0 2}$ & 88.19 & 103.02 \\
$\mathbf{1 9 8 3}$ & 24.32 & 23.60 & $\mathbf{1 9 9 3}$ & 53.14 & 54.42 & $\mathbf{2 0 0 3}$ & 92.88 & 106.94 \\
$\mathbf{1 9 8 4}$ & 26.01 & 25.57 & $\mathbf{1 9 9 4}$ & 58.67 & 59.98 & $\mathbf{2 0 0 4}$ & 99.02 & 110.97 \\
$\mathbf{1 9 8 5}$ & 27.22 & 26.99 & $\mathbf{1 9 9 5}$ & 64.37 & 66.12 & $\mathbf{2 0 0 5}$ & 103.37 & 115.68 \\
$\mathbf{1 9 8 6}$ & 28.72 & 29.34 & $\mathbf{1 9 9 6}$ & 67.24 & 72.05 & $\mathbf{2 0 0 6}$ & 109.59 & 122.90 \\
$\mathbf{1 9 8 7}$ & 30.73 & 31.93 & $\mathbf{1 9 9 7}$ & 70.32 & 77.21 & $\mathbf{2 0 0 7}$ & 114.94 & 130.75 \\
$\mathbf{1 9 8 8}$ & 33.41 & 34.80 & $\mathbf{1 9 9 8}$ & 74.41 & 87.43 & $\mathbf{2 0 0 8}$ & 124.92 & 141.67 \\
$\mathbf{1 9 8 9}$ & 35.66 & 36.89 & $\mathbf{1 9 9 9}$ & 77.03 & 91.51 & $\mathbf{2 0 0 9}$ & 127.86 & 157.08 \\
$\mathbf{1 9 9 0}$ & 38.89 & 40.20 & $\mathbf{2 0 0 0}$ & 81.84 & 95.18 & $\mathbf{2 0 1 0}$ & 140.08 & 175.92 \\
& & & & & & $\mathbf{2 0 1 1}$ & 153.35 & 191.50 \\
& & & & & & $\mathbf{2 0 1 2}$ & 164.93 & 209.33 \\
& & & & & & $\mathbf{2 0 1 3}$ & 175.35 & 232.17 \\
& & & & & & $\mathbf{2 0 1 4}$ & 182.03 & 246.92 \\
& & & & & & $\mathbf{2 0 1 5}$ & 177.03 & 261.42 \\
& & & & & & $\mathbf{2 0 1 6}$ & 179.89 & 273.56 \\
\hline
\end{tabular}

Note: Data based on average of Monthly data for obtaining Annual figure.

Source: RBI (www.rbi.org.in); Ministry of Statistics and Policy Implementation (www.mospi.gov.in)

Journal of Technology Management for Growing Economies, Volume 9, Number 2, October 2018
Inflationary

Trends in India 
Bala, I.

Sharma, D.

158

Graph 1- Consumer Price Index (CPI) and Wholesale Price Index (WPI)

Series 1981 to 2016

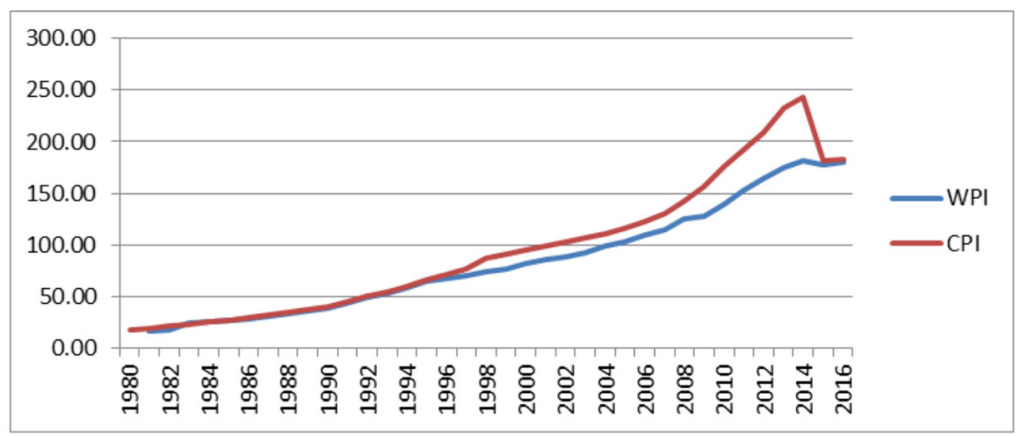

Source: Compiled from the Table 4.

The inflation chart and the Table 4 features an overview of the Indian inflation based on WPI and CPI since 1980. From the Table 4 and Graph 1, it appears that inflation, based on wholesale price index and CPI, has been continuously rising since 1980 except for few years. The lowest figure of WPI and CPI was recorded for the year 1981-82 and, while the highest one for WPI is 182.03 for the year 201314 and for CPI is 273.56 for the year 2015-16. The Trends can be studied into three time spans namely, pre-reform period (1980-90), Post reform period (1991-2000) and subsequent period (2001-16). Pre-reform period- for this phase, comparison of data is done over a period from 1980-81 to 1989-90. It can be seen from the Table 4 that both WPI and CPI registered a continuous increase in this phase. WPI and CPI inflation never entered the negative territory during this phase. Though the rate of increase is not uniform in both. In the post reform period the rate of increase in WPI is greater as compared to CPI and the third phase was very turbulent and severe in terms of the inflation, as it registered a big jump in WPI to 182.03 in the year 2014-15 and in CPI to 273.56 in the year 2015-16. It thus surfaces that there is a clear pattern of increase in the whole period.

Table 5: Trend Growth Rate: Consumer Price Index (CPI) and Wholesale Price Index (WPI) (1981-2016)

\begin{tabular}{|l|r|r|r|r|}
\hline & \multicolumn{2}{|c|}{ Trend Growth Rate } & \multicolumn{2}{c|}{ Standard Deviation } \\
\hline \multicolumn{1}{|c|}{ Period } & \multicolumn{1}{c|}{ WPI } & \multicolumn{1}{c|}{ CPI } & \multicolumn{1}{c|}{ WPI } & \multicolumn{1}{c|}{ CPI } \\
\hline Pre-Reform Period & 9.68 & 8.25 & 7.40 & 6.88 \\
\hline Post Reforms Period & 6.85 & 8.77 & 12.47 & 17.50 \\
\hline Subsequent Period & 5.78 & 7.45 & 35.25 & 61.45 \\
\hline Total & 6.83 & 7.68 & 51.73 & 73.8 \\
\hline
\end{tabular}

Source: Computed by the researcher.

Journal of Technology Management for Growing Economies, Volume 9, Number 2, October 2018 
It can be seen from the Table 5 that the Trend Growth Rate of WPI inflation was highest in the Pre-reform period as is clearly depicted in the Table 5 and the overall TGR stands out to be 6.83 percent. Whereas the Trend Growth Rate of CPI inflation was registered highest in the post reform period. The overall TGR of both the indicators is higher in CPI as compared to WPI.

Table 6: Correlation between WPI and CPI

\begin{tabular}{|l|l|}
\hline Period & Correlation Coefficient \\
\hline Pre-Reform Period & $\mathbf{. 7 9}^{*}(\mathbf{0 . 0 0})$ \\
\hline Post Reforms Period & $\mathbf{. 9 8 7}^{*}(\mathbf{0 . 0 1})$ \\
\hline Subsequent Period & $\mathbf{. 9 4}^{*}(\mathbf{0 . 0 0})$ \\
\hline Total & $\mathbf{. 9 8 6}^{*}(\mathbf{0 . 0 0 )}$ \\
\hline
\end{tabular}

Source: Computed by the researcher

* Insignificant values, Figures in Parentheses are P values

A look at Table 6 also reveals that the inflation rate based on both the indicators has been volatile, particularly during the Subsequent period. The volatility in WPI and CPI inflation is highest during this phase, as indicated by the standard deviation of 51.73 and 73.8 in WPI and CPI respectively. The highest volatility recorded is for the last phase. The fluctuations in WPI and CPI inflation are however moderate in the Pre-reform and post reform period, as is clear from the standard deviation of the same.

\section{MAJOR FINDINGS}

The major findings emerging out of the analysis can be stated as follows:

The weights of primary articles have declined in weights of whole sale price index whereas such weights have registered considerable increase in the categories of manufacturing and fuel and power. The shift in weights overtime provide us an indicator of the changing production and use pattern of the commodities in Indian set up. Moreover, the weights of traditional items have declined and it has increased in other items which are emerging important in the growth process.

The changes witnessed in weights of CPI are indicators of a growing economy. For, the weights of food items have reduced overtimes and such weights have been increased in terms of clothing, housing and fuel.

The inflation, based on WPI and CPI, has been continuously rising since 1980. Up to 1995, the trend in CPI and WPI were same and there was no significant difference between them. However, after 1994, CPI has recorded

Journal of Technology Management for Growing Economies, Volume 9, Number 2, October 2018
Inflationary

Trends in India 
Bala, I.

Sharma, D.

larger growth as compared to WPI. Besides, such trend continued in subsequent period. Such gap was more dramatic during this period. This is a question of major concern. Why such divergence has occurred? Conventionally the main reason for the CPI inflation being higher than WPI inflation is that food articles had a higher weight (48.3 per cent) in CPI than in WPI ( 24.3 per cent). The second main reason is the Non-food inflation. WPI and CPI have very different composition. Fuel and power category has a much bigger weight in WPI than in CPI. What is included in this category also differs very much. The third reason is that CPI includes "Service Sector", rising cost of education, health services leads to bigger CPI. As India grows, demand for services increases from urban middle class, due to which CPI increases.

During the period under study the CPI grew faster than WPI. Surprisingly, WPI grew faster than CPI during pre-reform period. However, the rate of growth in CPI was faster than WPI during the post reform period and subsequent periods. Inflation rate based on both the indicators has been volatile, particularly during the subsequent period. The volatility in WPI and CPI inflation is highest during this phase. The fluctuations in WPI and CPI inflation are however moderate in the Pre-reform and post reform period.

\section{CONCLUSION}

Nature of inflation during the period under study has been quite different. Prices of many commodities responsible for inflation during the pre-reform period did not register substantial increase during the post reform period and their place has been taken by other commodities. Prices of fuel, power, light and lubricants rose at a rapid rate in the post reform period. During the Post Reform period there had been higher increase in the prices of manufactured goods compared to that of agricultural commodities.

\section{REFERENCES}

Bishnoi, T. R. and Koirala, T. P. (2006) "Stability and Robustness of Inflation Model", Journal of Quantitative Economics, Vol. 4 (2), 114-130.

Callen, T. and Changl, D. (1999) "Modeling and Forecasting Inflation in India", IMF Working, WP / $99 / 119$, pp. 1-36.

Deshpande, A. and Sarkar, P. (1995) "Structural Adjustment in India: A Critical", Economic and Political Weekly, Vol. 30 (49), pp. 3151-3155.

Domac, I. and Carlos, E. (1998) "The Main Determinant of Inflation in Albania", World Bank Policy Research, Working Paper No. 1930.

Fischer, S. (1983) "Inflation and Growth NBER", Working Paper No. 1235.

Fisher Irving (1911) "The Purchasing Power of Money: Its Determination and Relation to Credit, Interest, and Crises. Macmillan (New York).

Gary, G. Moser (1995) "The Main Determinants of Inflation in Nigeria. IMF Staff Papers, Vol. 42 (2), pp. 270-289.

Hellerstein, R. (1997): The Impact of Inflation. Regional Review, Winter Issue, Federal Reserve Bank of Boston.

Journal of Technology Management for Growing Economies, Volume 9, Number 2, October 2018 
Janak Raj, Dhal, S. and Jain, R. (2008) “Imported Inflation: The Evidence from India”, Reserve Bank of India Occasional Paper, Vol. 29 (3).

John, R. M. (2003) "Inflation in India: An Analysis Using Post Liberalized Data", IGIDR WorkInflationary Trends in India ing Paper.

Lim, C. and Adedeji, O. S. (2000) "An Econometrics Analysis of the Determinants of Inflation in Turkey", IMF Working Paper, 97/170

Mosayed, P. and Mohammed, R. (2009) "Sources of Inflation in Iran: An Application of the Real Approach", International Journal of Applied Econometrics and Quantitative Studies, Vol.6 (1), pp. 61-76.

Pandit, V. (1993) "Controlling Inflation: Some Analytical and Empirical Issues", Economic and Political Weekly, Vol.28 (1), pp. 39-42.

Patra, D. and Partha, R. (2010) "Inflation Expectations and Monetary Policy in India: An Empirical Exploration", IMF Working Paper, WP/10/84, pp. 1-26.

Ritu and Naresh, K. (2013) "Trend and Pattern of Unemployment and Inflation in India", Edubeam Multidisciplinary- online Research Journal, Vol. 10(1).

Sahadudhen, I. (2012) "A Cointegration and Error Correction Approach to the Determinants of Inflation in India", International Journal of Economic Research, Vol.3 (1), pp. 105-112.

Smyth, D.J. (1994) "Inflation and Growth", Journal of Macroeconomics, Vol. 16(2), pp. 261270. http://dx.doi.org//10.1016/0164-0704(94)90070-1. 